\title{
Thermochemical Parameters of 3-Chloroaniline Complexes of Certain Bivalent Transition Metal Bromides
}

\author{
Pedro Oliver Dunstan*, Abdul Majeed Khan \\ Instituto de Química, Universidade Estadual de Campinas, Campinas, Brazil \\ Email: ${ }^{*}$ dunstan@iqm.unicamp.br
}

Received August 13, 2013; revised September 10, 2013; accepted September 18, 2013

Copyright (C) 2013 Pedro Oliver Dunstan, Abdul Majeed Khan. This is an open access article distributed under the Creative Commons Attribution License, which permits unrestricted use, distribution, and reproduction in any medium, provided the original work is properly cited.

\begin{abstract}
Complexes of general formula $\left[\mathrm{MBr}_{2}(3-\mathrm{clan})_{\mathrm{n}}\right]$ (where $\mathrm{M}$ is $\mathrm{Fe}, \mathrm{Ni}, \mathrm{Cu}$ or $\mathrm{Zn}$; 3-clan = m-chloroaniline; $\mathrm{n}$ is 1.5 or 2) were prepared and their characteristic properties, such as capillary MP; C, H, N, Br and metal contents; TG/DTG and DSC curves; and IR and electronic spectra were determined. By calorimetric measurements in solution, the values of some thermodynamic parameters of the complexes were determined. From these values, the standard enthalpies of the metal-nitrogen coordinated bonds were calculated, and the standard enthalpies of the formation of the gaseous phase complexes were estimated.
\end{abstract}

Keywords: Enthalpies of Formation; Thermodynamic; Coordinated Bond Enthalpies; Calorimetric Measurements

\section{Introduction}

The standard enthalpies of formation are fundamental characteristics of complexes. Thermodynamic data in the literature concerning the standard enthalpies of formation of coordinated bonds in complexes are limited. Additional compounds that divalent transition metal salts form with the aniline ligand and its derivatives are mentioned in the literature [1-26]. In a previous article [11], complexes formed by 4-chloroaniline with several divalent transition metal bromides were studied. In this work, the complexes formed by 3-chloroaniline with bromides of iron(II), nickel(II), cooper(II) and zinc(II) were studied. The thermodynamic characterization of these compounds is important because the finding concerning thermodynamic properties can be used to determine their applications in catalyses and in chromatographic separation of metal ions. Calorimetric measurements were performed to measure the strength of the metal-nitrogen coordinated bonds. Several correlations of the thermodynamic parameters published in the literature for aniline and 4-chloroaniline complexes with the parameters of the 3-chloroaniline complexes prepared in this study were also obtained. It is expected that the ligand 4-chloroaniline forms a weaker coordinated bond than 3-chloroanilne due to the inductive effect of the electron with-

\footnotetext{
${ }^{*}$ Corresponding author.
}

drawing chloro atom in the phenyl ring. The effect is stronger in the para-position than that in the meta-position. Aniline must form the stronger bond, because it does not have any substitution in the phenyl ring. The enthalpy of formation of the complexes derived from the gaseous-phase metal ions, bromide ions and 3-chloroaniline has been determined.

\section{Materials and Methods}

\subsection{Reagents}

The purity of 3-chloroaniline (98\%, Aldrich) was improved by the method of Riddick [27]. The anhydrous metal dibromides used in the synthesis were of analytical grade. Solvents were distilled and stocking over Linde 4 Å molecular sieves before using.

\subsection{Experimental Procedure}

Complexes were obtained by reacting the metal dibromides and 3-chloroaniline in solution. Hot ethanol was used as a solvent with a molar ratio salt/ligand of $1 / 4$. The following is an example of the preparations: $1.10 \mathrm{~g}$ of $\mathrm{NiBr}_{2}\left(5.03 \times 10^{-3} \mathrm{~mol}\right)$ was dissolved in $20 \mathrm{~mL}$ of hot ethanol $(343 \mathrm{~K})$, and $2.57 \mathrm{~g}\left(2.13 \mathrm{~mL}, 20.13 \times 10^{-3} \mathrm{~mol}\right)$ of 3 -chloroaniline was poured into the solution of the salt, slowly and dropwise. The stirring was maintained after 
the complete addition of the ligand. A green solid was formed which was filtered and washed with $60 \mathrm{~mL}$ of petroleum ether divided in three portions. The compound obtained was maintained in a vacuum over several hours. It was stocked in a desiccator over $\mathrm{CaCl}_{2}$. The chemical analysis confirmed the contents proposed by the assumed stoichiometries. Microanalytical procedures [28] were used for the determination of $\mathrm{C}, \mathrm{H}$ and $\mathrm{N}$ contents. The bromine contents were determined by gravimetric analysis [29]. The metal contents were complexometrically determined using $0.01 \mathrm{M}$ ethylenediaminetetraacetic acid solution [30]. Samples of the compounds in a $\mathrm{KBr}$ matrix were used to obtain the IR spectra. For the ligand, a film of it between $\mathrm{KBr}$ plates was used. The region was from 4000 to $400 \mathrm{~cm}^{-1}$ and a Perkin Elmer 1600 series FTIR Spectrophotometer was used. A UV-Vis-NIR VarianCary SG spectrophotometer was used to record the spectra of the compounds in the region of $350-2000 \mathrm{~nm}$ using a standard reflectance attachment to obtain the spectra of the solid compounds. TG/DTG and DSC curves were recorded in an argon atmosphere in a Du Pont 951 analyzer. The mass of the samples was initially between 6.37 and $8.79 \mathrm{mg}$ (TG/DTG) and from 2.65 to $4.47 \mathrm{mg}$ (DSC). A heating rate of $10 \mathrm{~K} \cdot \mathrm{min}^{-1}$ was used from 298 to $678 \mathrm{~K}$ (DSC) and from 298 to $1248 \mathrm{~K}$ (TG/DTG). The calibration for temperatures was made with metallic aluminum as a standard (mp $933.49 \mathrm{~K}$ ). The equipment performed the calibration for mass automatically. The DSC calibration was conducted with metallic indium as a standard $\left(\mathrm{mp}=438.85 \mathrm{~K}, \Delta_{\mathrm{s}}^{1} H^{\circ}=28.4 \mathrm{~J} \cdot \mathrm{g}^{-1}\right)$. For the calorimetric study of the compounds, an LKB 8700-1 precision calorimeter was used. The temperature of the measurements was $298.15 \pm 0.02 \mathrm{~K}$. A thin-walled ampoule that contained reactant was broken in a glass reaction vessel filled with $(100.00 \mathrm{~mL})$ of calorimetric solvent [31]. The accuracy of the equipment was determined as previously reported [31,32]. Three to six replicate measurements were made on each compound and the uncertainty intervals are twice the standard deviations. The experimental deviations of the dissolution measurements were between $(0.7 \%-2.8 \%)$.

\section{Results}

\subsection{Complex Characterization}

All complexes were solids. The interaction of $\mathrm{MnBr}_{2}$ and $\mathrm{CoBr}_{2}$ with 3-chloroaniline did not lead to the formation of compounds with a definite stoichiometry. The outcomes of the synthesis, capillary mp, colors, appearance, and elemental contents are presented in Table 1.

\subsection{Infrared Spectra}

Some absorption bands of the compounds are presented in Table 2. The band attributed to the stretching vibration of the NH group $\left(v_{(\mathrm{N}-\mathrm{H})}\right)$ in the free ligand is shifted towards lower frequencies in the coordinated ligand. This is observed when aniline and aniline derivatives coordinates to the metal ions [33,34]. Figure 1 presents the IR spectra of the $\mathrm{Cu}$ (II) adduct.

\subsection{Thermal Studies}

The (TG/DTG) curves of the $\mathrm{Cu}$ and $\mathrm{Zn}$ complexes showed the elimination of all the ligand in three steps of mass loss, with the elimination of all the bromine content together with part of the metal content in the third stage of mass loss. The curve of the complex of Fe showed the mass of the ligand being eliminated in three stages with part of the bromine content being eliminated in the third stage together with part of the ligand content followed by the elimination of part of the bromine content in a fourth stage of mass loss. The curve of the complex of $\mathrm{Ni}$ showed the elimination of all the ligand in two stages with the elimination of part of the bromine content in a third stage of mass loss. The TG/DTG curves showed a residue that is the metal content plus part of the bromine content for the complexes of $\mathrm{Fe}$ and $\mathrm{Ni}$. This residue is part of the metal content for the complexes of $\mathrm{Cu}$ and $\mathrm{Zn}$. Figure 2 presents the TG/DTG curve of the Ni(II) complex. The DSC curves of the complexes show endothermic peaks that are consistent with the elimination of part of the ligand. Figure 3 presents the DSC curve of the

Table 1. Melting points, yields, appearance and analytical data* of the complexes.

\begin{tabular}{|c|c|c|c|c|c|c|c|c|c|c|c|c|c|}
\hline \multirow[t]{2}{*}{ COMPOUND } & \multirow{2}{*}{$\begin{array}{c}\text { YIELD } \\
\%\end{array}$} & \multirow{2}{*}{$\frac{\mathrm{MP}^{\mathrm{A}}}{\mathrm{K}}$} & \multirow[t]{2}{*}{ APPEAR. ${ }^{B}$} & \multicolumn{2}{|c|}{$\% \mathrm{C}$} & \multicolumn{2}{|c|}{$\% \mathrm{H}$} & \multicolumn{2}{|c|}{$\% \mathrm{~N}$} & \multicolumn{2}{|c|}{$\% \mathrm{Br}$} & \multicolumn{2}{|c|}{$\% \mathrm{M}$} \\
\hline & & & & Calc. & Found & Calc. & Found & Calc. & Found & Calc. & Found & Calc. & Found \\
\hline$\left[\mathrm{FeBr}_{2}(3-\mathrm{lan})_{1.5}\right]$ & 17 & $500-3$ & b.p. & 26.53 & $\begin{array}{c}26.28 \\
(-0.94)\end{array}$ & 2.23 & $\begin{array}{c}2.43 \\
(8.97)\end{array}$ & 5.16 & $\begin{array}{c}5.88 \\
(13.95)\end{array}$ & 39.26 & $\begin{array}{c}38.84 \\
(-1.07)\end{array}$ & 13.72 & $\begin{array}{c}13.33 \\
(-2.84)\end{array}$ \\
\hline$\left[\mathrm{NiBr}_{2}(3 \text {-clan })_{1.5}\right]$ & 64 & $392-5$ & l.g.p. & 26.35 & $\begin{array}{l}26.81 \\
(1.75)\end{array}$ & 2.21 & $\begin{array}{c}2.58 \\
(16.74)\end{array}$ & 5.12 & $\begin{array}{c}5.19 \\
(1.37)\end{array}$ & 38.99 & $\begin{array}{c}38.20 \\
(-2.03)\end{array}$ & 14.32 & $\begin{array}{c}13.93 \\
(-2.72)\end{array}$ \\
\hline$\left[\mathrm{CuBr}_{2}(3-\mathrm{clan})_{2}\right]$ & 56 & $446-500$ & d.b. p. & 30.09 & $\begin{array}{c}29.54 \\
(-1.83)\end{array}$ & 2.52 & $\begin{array}{c}2.13 \\
(-15.48)\end{array}$ & 5.85 & $\begin{array}{c}5.49 \\
(-6.15)\end{array}$ & 35.77 & $\begin{array}{c}35.13 \\
(-0.18)\end{array}$ & 13.28 & $\begin{array}{c}12.98 \\
(-2.26)\end{array}$ \\
\hline$\left[\mathrm{ZnBr}_{2}(3-\text { clan })_{2}\right]$ & 84 & $387-90$ & w.p. & 29.97 & $\begin{array}{l}30.04 \\
(0.23)\end{array}$ & 2.51 & $\begin{array}{c}2.37 \\
(-5.58)\end{array}$ & 5.82 & $\begin{array}{c}5.72 \\
(-1.72)\end{array}$ & 33.26 & $\begin{array}{l}33.78 \\
(1.56)\end{array}$ & 13.61 & $\begin{array}{c}13.40 \\
(-1.54)\end{array}$ \\
\hline
\end{tabular}

${ }^{\mathrm{A}}$ Melting with decomposition. ${ }^{\mathrm{B}}$ Key: b., brown; g., green; w., white; 1., light; d., dark; p., powder. ${ }^{*}$ (Standard deviation errors, \%). 
Table 2. Main IR spectral data $\left(\mathrm{cm}^{-1}\right)$ of the complexes.

\begin{tabular}{ccc}
\hline Compound & $\boldsymbol{v}_{(\mathrm{N}-\mathrm{H})}$ & $\boldsymbol{\delta}_{(\mathrm{N}-\mathrm{H})}$ \\
\hline 3-clan & $3444 \mathrm{~m}, 3362 \mathrm{~m}$ & $1602 \mathrm{~s}, 1597 \mathrm{~s}$ \\
{$\left[\mathrm{FeBr}_{2}(3 \text {-clan) })_{1.5}\right]$} & $3430 \mathrm{~s}, 2875 \mathrm{~s}, 2825 \mathrm{~s}$ & $1596 \mathrm{~m}, 1564 \mathrm{~m}$ \\
{$\left[\mathrm{NiBr}_{2}(3 \text {-clan) })_{1.5}\right]$} & $3405 \mathrm{~s}, 3329 \mathrm{~s}$ & $1602 \mathrm{~s}, 1578 \mathrm{~m}$ \\
$\left.\mathrm{CuBr}_{2}(3 \text {-clan })_{2}\right]$ & $3434 \mathrm{~m}, 3291 \mathrm{~s}, 3231 \mathrm{~s}$ & $1592 \mathrm{~s}, 1560 \mathrm{~m}$ \\
$\left.\mathrm{ZnBr}_{2}(3 \text {-clan })_{2}\right]$ & $3436 \mathrm{~m}, 3263 \mathrm{~s}, 3215 \mathrm{~s}$ & $1598 \mathrm{~s}, 1573 \mathrm{~m}$ \\
\hline
\end{tabular}

Key: $v$, stretching; $\delta$, angular deformation. Intensity of bands: s, strong; $\mathrm{m}$. medium.

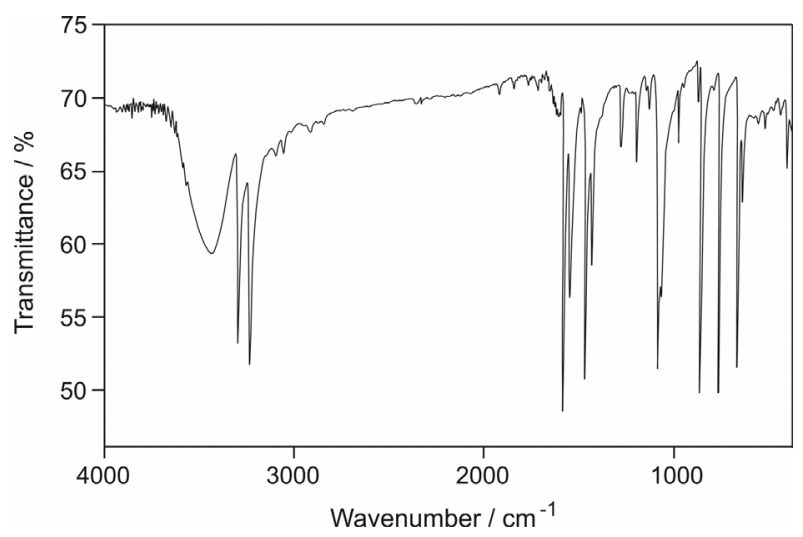

Figure 1. Infrared spectrum of the complex $\left[\mathrm{CuBr}_{2}(3-\mathrm{clan})_{2}\right]$.

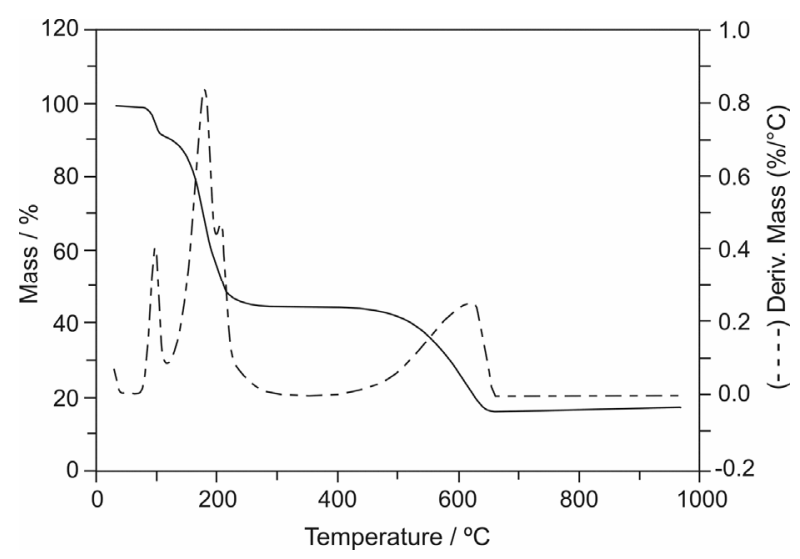

Figure 2. TG/DTG curve of the complex $\left[\mathrm{NiBr}_{2}(3-\mathrm{clan})_{1.5}\right]$.

Ni(II) complex. Table 3 shows the thermal data obtained for the complexes. Discrepancies between the calculated and observed mass losses are due to losses through the TG curve between one step and the following step of mass loss.

\subsection{Electronic Spectra}

The complex of Ni showed the metal ions in the center of pseudo-octahedral units $\left[\mathrm{NiL}_{2} \mathrm{Br}_{4}\right]^{2-}$ and $\left[\mathrm{NiLBr}_{5}\right]^{3-}$ forming a three-dimensional polymer. This was con-

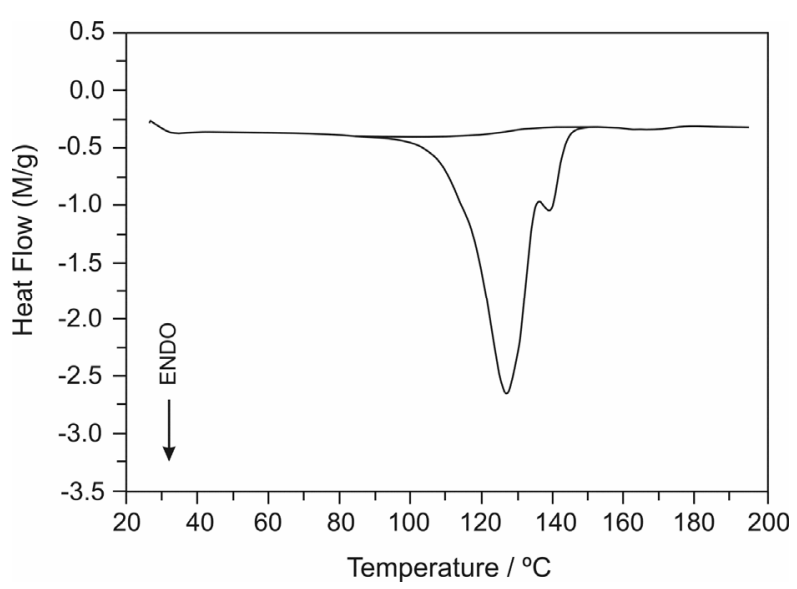

Figure 3. DSC curve of the complex $\left[\mathrm{NiBr}_{2}(3-\mathrm{clan})_{1.5}\right]$.

cluded from the values of the calculated ligand field parameters and the positions of the absorption bands $[35,36]$. The complex of Fe showed the metal ions in the center of pseudo-octahedral units $\left[\mathrm{FeL}_{2} \mathrm{Br}_{4}\right]^{2-}$ and $\left[\mathrm{FeLBr}_{5}\right]^{3-}$ forming a three-dimensional polymer. This was concluded from the values of the calculated ligand field parameter and position of the absorption band [37]. The $\mathrm{Cu}$ complex showed the metal ion in the center of pseudo-tetrahedrons $\left[\mathrm{CuL}_{2} \mathrm{Br}_{2}\right]$. This was concluded from the appearance and position of the broth absorption band at $\left(15,862 \mathrm{~cm}^{-1}\right)$ [37]. Table 4 presents the attribution of the absorption bands and the calculated values of the ligand field parameters for the compounds.

\subsection{Calorimetric Measurements}

The solution enthalpy measurements of the compounds were made accordingly to the following reactions [38]:

$$
\begin{gathered}
\mathrm{MBr}_{2(\mathrm{~s})}+\text { selected solvent } \rightarrow \text { solution } \mathrm{a} ; \quad \Delta_{1} H^{\mathrm{o}} \\
\mathrm{n}(3 \text {-clan }(1))+\text { solution } \mathrm{a} \rightarrow \text { solution } \mathrm{b} ; \quad \Delta_{2} H^{\mathrm{o}} \\
{\left[\mathrm{MBr}_{2}(3 \text {-clan })_{\mathrm{n}}\right]_{(\mathrm{s})}+\text { selected solvent }} \\
\rightarrow \text { solution c; } \quad \Delta_{3} H^{\mathrm{o}} \\
\text { solution } \mathrm{b} \rightarrow \text { solution } \mathrm{c} ; \quad \Delta_{4} H^{\mathrm{o}}
\end{gathered}
$$

According to Hess'law for the reactions (1)-(4), the standard enthalpy of reaction $\left(\Delta_{\mathrm{r}} H^{\theta}\right)$ of the following reaction:

$$
\mathrm{MBr}_{2(\mathrm{~s})}+\mathrm{n}\left(3-\operatorname{clan}_{(1)}\right) \rightarrow\left[\mathrm{MBr}_{2}(3-\mathrm{clan})_{\mathrm{n}}\right]_{(\mathrm{s})} ; \quad \Delta_{\mathrm{r}} H^{\mathrm{o}}
$$

is equal to: $\Delta_{\mathrm{r}} H^{\mathrm{o}}=\Delta_{1} H^{\mathrm{o}}+\Delta_{2} H^{\mathrm{o}}-\Delta_{3} H^{\mathrm{o}}$, because the final state of reactions (2) and (3) is the same and $\Delta_{4} H^{\theta}=$ 0 , and also because the dilution of solution $b$ into solution $\mathrm{c}$ has no thermal effect. Table 5 presents the values 
Table 3. Thermal analysis of the compounds.

\begin{tabular}{|c|c|c|c|c|c|c|c|}
\hline Compound & App. MP/K & \multicolumn{2}{|c|}{ mass loss $(\%)$} & TG temp. range/K & Species lost & DSC p. temp. & $\Delta H^{\circ}$ \\
\hline & & Calcd. & Obs. $^{b}$ & & & & $\mathrm{~kJ} \cdot \mathrm{mol}^{-1}$ \\
\hline \multirow[t]{5}{*}[\mathrm{FeBr}_{2}(3\text{-clan})_{1.5}]{} & $500-503$ & 28.20 & $28.98(6.31 \%)$ & $361-409$ & $-0.9 \mathrm{~L}$ & 386 & 39.13 \\
\hline & & 10.97 & $11.07(0.91 \%)$ & $409-534$ & $-0.35 \mathrm{~L}$ & 398 & 17.96 \\
\hline & & 23.54 & $23.99(1.91 \%)$ & $534-872$ & $0.25 \mathrm{~L}-0.8 \mathrm{Br}$ & 423 & 19.27 \\
\hline & & 19.63 & $19.61(-5.19 \%)$ & $872-1136$ & $-\mathrm{Br}$ & & \\
\hline & & & $15.00^{\mathrm{a}}$ & & & & \\
\hline \multirow[t]{4}{*}[\mathrm{NiBr}_{2}(3\text{-clan})_{1.5}]{} & $392-395$ & 3.11 & $3.08(-0.96 \%)$ & $360-361$ & $-0.1 \mathrm{~L}$ & 387 & 96.73 \\
\hline & & 49.79 & $47.73(-4.86 \%)$ & $361-482$ & $-1.4 \mathrm{~L}$ & 431 & 0.71 \\
\hline & & 27.30 & $27.73(1.58 \%)$ & $806-916$ & $-1.4 \mathrm{Br}$ & & \\
\hline & & & $21.82^{\mathrm{a}}$ & & & & \\
\hline \multirow[t]{4}{*}[\mathrm{CuBr}_{2}(3\text{-clan})_{2}]{} & $446-450$ & 31.99 & $32.29(0.94 \%)$ & $376-415$ & $-1.2 \mathrm{~L}$ & 393 & 57.22 \\
\hline & & 10.66 & $11.18(-4.88 \%)$ & $415-552$ & $-0.4 \mathrm{~L}$ & & \\
\hline & & 54.02 & $53.67(-0.65 \%)$ & $552-1005$ & $-0.4 \mathrm{~L}-2 \mathrm{Br}-0.75 \mathrm{Cu}$ & & \\
\hline & & & $2.69^{\mathrm{a}}$ & & & & \\
\hline \multirow[t]{4}{*}[\mathrm{ZnBr}_{2}(3-\mathrm{clan})_{2}]{} & $387-390$ & 39.84 & $40.12(0.70 \%)$ & $450-485$ & $-1.5 \mathrm{~L}$ & 537 & 74.45 \\
\hline & & 9.30 & $9.34(0.43 \%)$ & $485-658$ & $-0.35 \mathrm{~L}$ & & \\
\hline & & 44.43 & $45.19(1.71 \%)$ & $658-712$ & $-0.15 \mathrm{~L}-2 \mathrm{Br}-0.6 \mathrm{Zn}$ & & \\
\hline & & & $5.35^{\mathrm{a}}$ & & & & \\
\hline
\end{tabular}

${ }^{\mathrm{a}}$ Residue at $1243 \mathrm{~K} .{ }^{\mathrm{b}}$ (standard deviation errors).

Table 4. Band maxima and calculated ligand field parameters of the complexes.

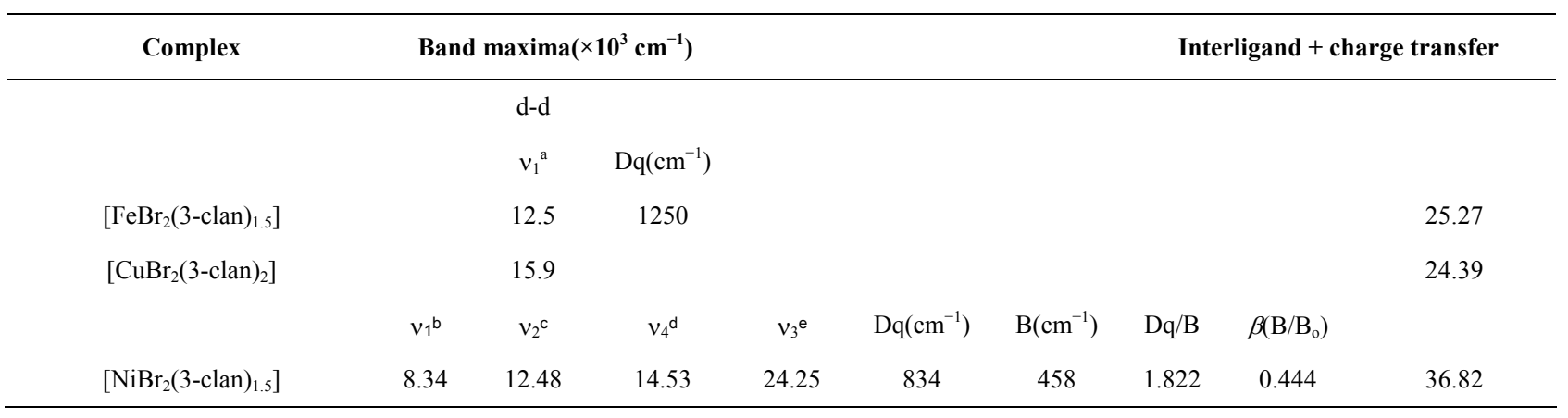

Key: ${ }^{\mathrm{a}} v_{1}={ }^{5} \mathrm{E}_{\mathrm{g}} \leftarrow{ }^{5} \mathrm{~T}_{2 \mathrm{~g}} ;{ }^{\mathrm{b}} v_{1}={ }^{3} \mathrm{~T}_{2 \mathrm{~g}} \leftarrow{ }^{3} \mathrm{~A}_{2 \mathrm{~g}} ;{ }^{\mathrm{c}} v_{2}={ }^{3} \mathrm{~T}_{1 \mathrm{~g}}(\mathrm{~F}) \leftarrow^{3} \mathrm{~A}_{2 \mathrm{~g}} ;{ }^{\mathrm{d}} v_{4}={ }^{1} \mathrm{E}_{\mathrm{g}} \leftarrow{ }^{3} \mathrm{~A}_{2 \mathrm{~g}} ;{ }^{\mathrm{e}} v_{3}={ }^{3} \mathrm{~T}_{1 \mathrm{~g}}(\mathrm{P}) \leftarrow{ }^{3} \mathrm{~A}_{2 \mathrm{~g}} ; \beta=\mathrm{B} / \mathrm{B}_{0} ; \mathrm{B}_{0}=1030 \mathrm{~cm}^{-1}[37]$.

obtained for the dissolution enthalpies: $\left(\Delta_{1} H^{\circ}\right)$ for the dissolution of $\mathrm{MBr}_{2}$ (solution a); $\left(\Delta_{2} H^{\circ}\right)$ for the dissolution of the ligand in the former solution, with respect to the stoichiometry of the ligand in the later solution, respecting the stoichiometry of the complex (solution b); and $\left(\Delta_{3} H^{\circ}\right)$ for the dissolution of the complexes (solution c). This table presents the uncertainty intervals as twice the standard deviation of the means of $(3-6)$ replicate measurements. Using thermochemical cycles [38] and the calculated values for the enthalpies of reaction (5) $\left(\Delta_{\mathrm{r}} H^{\mathrm{o}}\right)$, the thermochemical parameters for the complexes were estimated. Table 6 presents the values obtained for these enthalpies.

\section{Discussions}

The standard enthalpy of decomposition is defined by the equation:

$$
\operatorname{MBr}_{2}(3-\operatorname{clan})_{\mathrm{n}} \rightarrow \mathrm{MBr}_{2(\mathrm{~s})}+\mathrm{n}\left(3-\operatorname{clan}_{(1)}\right) ; \quad \Delta_{\mathrm{D}} H^{\mathrm{o}}
$$

where $\Delta_{\mathrm{D}} H^{\mathrm{o}}=-\Delta_{\mathrm{r}} H^{\mathrm{o}}+\mathrm{n} \Delta_{1}^{\mathrm{g}} H^{\mathrm{o}}(3$-clan $)$.

The standard lattice enthalpy is defined by 
Table 5. Enthalpies of dissolution at $298.15 \mathrm{~K}$.

\begin{tabular}{|c|c|c|c|c|}
\hline Complex & Calorimetric Solvent & Number of & $\mathrm{i}$ & $\Delta_{\mathrm{i}} H$ \\
\hline & & experiments $^{\mathrm{a}}$ & & $\mathrm{kJ} \cdot \mathrm{mol}^{-1}$ \\
\hline $\mathrm{FeBr}_{2(\mathrm{~s})}$ & $1.2 \mathrm{M}$ aq. $\mathrm{HCl}$ & 5 & 1 & $-70.25 \pm 0.71$ \\
\hline $3-\operatorname{clan}_{(1)}$ & 1.5:1 $\mathrm{FeBr}_{2}-1.2 \mathrm{M}$ aq. $\mathrm{HCl}$ & 5 & 2 & $-33.07 \pm 0.92$ \\
\hline$\left[\mathrm{FeBr}_{2}(3-\mathrm{clan})_{1.5}\right]_{(\mathrm{s})}$ & $1.2 \mathrm{M}$ aq. $\mathrm{HCl}$ & 4 & 3 & $10.50 \pm 0.44$ \\
\hline $\mathrm{NiBr}_{2(\mathrm{~s})}$ & $1.2 \mathrm{M}$ aq. $\mathrm{HCl}$ & 5 & 1 & $48.05 \pm 0.35$ \\
\hline $3-\operatorname{clan}_{(1)}$ & $1.5: 1 \mathrm{NiBr}_{2}-1.2 \mathrm{M}$ aq. $\mathrm{HCl}$ & 4 & 2 & $-35.83 \pm 0.86$ \\
\hline$\left[\mathrm{NiBr}_{2}(3-\mathrm{clan})_{1.5}\right]_{(\mathrm{s})}$ & $1.2 \mathrm{M}$ aq. $\mathrm{HCl}$ & 4 & 3 & $-14.94 \pm 0.36$ \\
\hline $\mathrm{CuBr}_{2(\mathrm{~s})}$ & $1.2 \mathrm{M}$ aq. $\mathrm{HCl}$ & 3 & 1 & $-17.98 \pm 0.13$ \\
\hline $3-\operatorname{clan}_{(1)}$ & 2:1 $\mathrm{CuBr}_{2}-1.2 \mathrm{M}$ aq. $\mathrm{HCl}$ & 3 & 2 & $-34.11 \pm 0.40$ \\
\hline$\left[\mathrm{CuBr}_{2}(3-\mathrm{Clan})_{2}\right]_{(\mathrm{s})}$ & $1.2 \mathrm{M}$ aq. $\mathrm{HCl}$ & 5 & 3 & $17.87 \pm 0.48$ \\
\hline $\mathrm{ZnBr}_{2(\mathrm{~s})}$ & $1.2 \mathrm{M}$ aq. $\mathrm{HCl}$ & 6 & 1 & $-39.13 \pm 0.60$ \\
\hline $3-\operatorname{clan}_{(1)}$ & 2:1 $\mathrm{ZnBr}_{2}-1.2 \mathrm{M}$ aq. $\mathrm{HCl}$ & 4 & 2 & $-48.04 \pm 0.88$ \\
\hline$\left[\mathrm{ZnBr}_{2}(3-\text { clan })_{2}[]_{(\mathrm{s})}\right.$ & $1.2 \mathrm{M}$ aq. $\mathrm{HCl}$ & 5 & 3 & $9.36 \pm 0.29$ \\
\hline
\end{tabular}

${ }^{\mathrm{a}}$ Experimental data available after applying for.

Table 6. Summary of the thermochemical results $\left(\mathrm{kJ} \cdot \mathrm{mol}^{-1}\right)$ for the complexes.

\begin{tabular}{|c|c|c|c|c|c|c|c|}
\hline Complex & $\Delta_{\mathrm{r}} H^{\mathrm{o}}$ & $\Delta_{\mathrm{f}} H^{\mathrm{o}}$ & $\Delta_{\mathrm{s}, 1}{ }^{\mathrm{g}} H^{\mathrm{o}}$ & $\Delta_{\mathrm{M}} H^{\mathrm{o}}$ & $\Delta_{\mathrm{D}} H^{\circ}$ & $\Delta_{\mathrm{r}} H^{\mathrm{o}}(\mathrm{g})$ & $\bar{D}_{(\mathrm{M}-\mathrm{N})}$ \\
\hline $\mathrm{FeBr}_{2(\mathrm{~s})}$ & $-249.8[40]$ & $204[40]$ & & & & & \\
\hline $\mathrm{NiBr}_{2(\mathrm{~s})}$ & $-212.1[40]$ & $170[40]$ & & & & & \\
\hline $\mathrm{CuBr}_{2(\mathrm{~s})}$ & $-141.8[40]$ & $182.4[40]$ & & & & & \\
\hline $\mathrm{ZnBr}_{2(\mathrm{~s})}$ & $-328.65[40]$ & $159.7[40]$ & & & & & \\
\hline $3-\operatorname{clan}_{(I)}$ & $-11.8[40]$ & $61.9[41]$ & & & & & \\
\hline$\left[\mathrm{FeBr}_{2}(3-\mathrm{clan})_{1.5}\right]_{(\mathrm{s})}$ & $-113.82 \pm 1.24$ & $-381.3 \pm 3.1$ & $233 \pm 11[39]$ & $-411 \pm 4$ & $206.7 \pm 3.2$ & $-178 \pm 12$ & $119 \pm 8$ \\
\hline$\left[\mathrm{NiBr}_{2}(3-\mathrm{clan})_{1.5}\right]_{(\mathrm{s})}$ & $-68.94 \pm 1.00$ & $-298.7 \pm 2.4$ & $199 \pm 11[39]$ & $-332 \pm 3$ & $161.8 \pm 3.2$ & $-133 \pm 11$ & $89 \pm 7$ \\
\hline$\left[\mathrm{CuBr}_{2}(3-\mathrm{clan})_{2}\right]_{(\mathrm{s})}$ & $-69.96 \pm 0.65$ & $-235.4 \pm 4.5$ & $212 \pm 11[39]$ & $-376 \pm 4$ & $193.8 \pm 4.1$ & $-165 \pm 12$ & $83 \pm 6$ \\
\hline$\left[\mathrm{ZnBr}_{2}(3 \text {-clan })_{2}\right]_{(\mathrm{s})}$ & $-96.53 \pm 1.10$ & $448.8 \pm 4.6$ & $189 \pm 11[39]$ & $-380 \pm 5$ & $220.3 \pm 4.1$ & $-191 \pm 12$ & $96 \pm 6$ \\
\hline
\end{tabular}

$$
\mathrm{MBr}_{2(\mathrm{~g})}+\mathrm{n}(3-\mathrm{clan})_{(\mathrm{g})} \rightarrow\left[\mathrm{MBr}_{2}(3-\mathrm{clan})_{\mathrm{n}}\right]_{(\mathrm{s})} ; \Delta_{\mathrm{M}} H^{\mathrm{o}}
$$

where $\Delta_{\mathrm{M}} H^{\mathrm{o}}=-\Delta_{\mathrm{D}} H^{\mathrm{o}}-\Delta_{\mathrm{s}}^{\mathrm{g}} H^{\mathrm{o}}\left(\mathrm{MBr}_{2}\right)$

The standard enthalpy of reaction in the gaseous phase is defined by the equation:

$$
\mathrm{MBr}_{2(\mathrm{~g})}+\mathrm{n}(3-\text { clan })_{(\mathrm{g})} \rightarrow\left[\operatorname{MBr}_{2}(3-\mathrm{clan})_{\mathrm{n}}\right]_{(\mathrm{g})} ; \Delta_{\mathrm{r}} H^{\mathrm{o}}(\mathrm{g})
$$

where

$$
\begin{aligned}
\Delta_{\mathrm{r}} H^{\mathrm{o}}(\mathrm{g})= & -\Delta_{\mathrm{s}}^{\mathrm{g}} H^{\mathrm{o}}\left(\mathrm{MBr}_{2(\mathrm{~s})}\right)-\mathrm{n} \Delta_{1}^{\mathrm{g}} H^{\mathrm{o}}\left(3-\operatorname{clan}_{(1)}\right) \\
& +\Delta_{\mathrm{r}} H^{\mathrm{o}}+\Delta_{\mathrm{s}}^{\mathrm{g}} H^{\mathrm{o}}\left(\operatorname{complex}_{(\mathrm{s})}\right)
\end{aligned}
$$

As the complexes decomposed on heating, the enthalpies of sublimation of the adducts were estimated [39]. The standard enthalpies of the metal(II)-nitrogen bonds are obtained from reaction (8) [40]:

$\bar{D}_{(\mathrm{M}-\mathrm{N})}=-\left(\Delta_{\mathrm{r}} H^{\mathrm{o}}(\mathrm{g}) / \mathrm{n}\right)$. Table 6 presents the values obtained for all of the enthalpies. The formation enthalpies of the complexes in the gaseous phase according to reaction (9):

$$
\mathrm{M}_{(\mathrm{g})}^{2+} 2 \mathrm{Br}_{(\mathrm{g})}^{-}+\mathrm{n}\left(3-\operatorname{clan}_{(\mathrm{g})}\right) \rightarrow\left[\mathrm{MBr}_{2}(3-\mathrm{clan})_{\mathrm{n}}\right]_{(\mathrm{g})} ; \Delta_{\mathrm{fl}} H^{\mathrm{o}}
$$

are equal to:

$$
\begin{aligned}
\Delta_{\mathrm{fl}} H^{\theta}= & \Delta_{\mathrm{f}} H^{\theta}\left(\operatorname{complex}_{(\mathrm{g})}\right)-\Delta_{\mathrm{f}} H^{\theta}\left(\mathrm{M}_{(\mathrm{g})}^{2+}\right) \\
& -2 \Delta_{\mathrm{f}} H^{\theta}\left(\mathrm{Br}_{(\mathrm{g})}^{-}\right)-\mathrm{n} \Delta_{\mathrm{f}} H^{\theta}\left(3-\operatorname{clan}_{(\mathrm{g})}\right)
\end{aligned} .
$$

Table 7 presents the values obtained for these enthalpy values. The acidity order was obtained based on the $\Delta_{\mathrm{r}} H^{\theta}$ or $\bar{D}$ values for the complexes. Complexes of 
Table 7. Auxiliary data and enthalpy changes of the ionic complex formation process in the gaseous phase $\left(\mathrm{kJ} \cdot \mathrm{mol}^{-1}\right)$.

\begin{tabular}{cccc}
\hline Compound & $\Delta_{\mathrm{f}} \boldsymbol{H}^{\theta}$ & $\Delta_{\mathrm{r}} \boldsymbol{H}^{\theta}(\mathbf{g})$ & $\Delta_{\mathrm{fl}} \boldsymbol{H}^{\theta}$ \\
\hline $\mathrm{Br}_{(\mathrm{g})}{ }^{-}$ & $-219.07[42]$ & & \\
$\mathrm{Fe}_{(\mathrm{g})^{2+}}$ & $2751.6 \pm 2.3[42]$ & & \\
$\mathrm{Ni}_{(\mathrm{g})}^{2+}$ & $2930.5 \pm 1.5[42]$ & & \\
$\mathrm{Cu}_{(\mathrm{g})}{ }^{2+}$ & $3054.5 \pm 2.1[42]$ & & \\
$\mathrm{Zn}_{(\mathrm{g})}{ }^{2+}$ & $2781.0 \pm 0.4[42]$ & & \\
{$\left[\mathrm{FeBr}_{2}(3 \text {-clan })_{1.5}\right]_{(\mathrm{g})}$} & $-149 \pm 12$ & $-178 \pm 12$ & $-2742 \pm 12$ \\
{$\left[\mathrm{NiBr}_{2}(3 \text {-clan })_{1.5}\right]_{(\mathrm{g})}$} & $-100 \pm 11$ & $-133 \pm 11$ & $-2668 \pm 11$ \\
{$\left[\mathrm{CuBr}_{2}(3 \text {-clan })_{2}\right]_{(\mathrm{g})}$} & $-24 \pm 12$ & $-165 \pm 12$ & $-2741 \pm 13$ \\
{$\left[\mathrm{ZnBr}_{2}(3 \text {-clan })_{2}\right]_{(\mathrm{g})}$} & $-260 \pm 12$ & $-191 \pm 12$ & $-2922 \pm 12$ \\
\hline
\end{tabular}

the same stoichiometry were compared. The acidity order is: $\mathrm{FeBr}_{2}>\mathrm{NiBr}_{2}$ and $\mathrm{ZnBr}_{2}>\mathrm{CuBr}_{2}$. The basicity order was obtained based on the $\Delta_{\mathrm{r}} H^{\theta}$ values of the complexes of 3-clan and 4-clan [42] of the same stoichiometry. The basicity order is: 3-clan > 4-clan (for $\left.\mathrm{CuBr}_{2}\right)$ and 3-clan > 4-clan (for $\mathrm{ZnBr}_{2}$ ). Comparing the $\Delta_{\mathrm{r}} H^{\theta}$ values for complexes of aniline (an) [43] of the same stoichiometry, the basicity order is: an $>3$-clan (for $\mathrm{CuBr}_{2}$ ) and an $>3$-clan (for $\mathrm{ZnBr}_{2}$ ). As a whole, the basicity order is: an $>3$-clan $>$ 4-clan (for $\mathrm{CuBr}_{2}$ and $\mathrm{ZnBr}_{2}$ ). Using the $\bar{D}$ values the order is: an > 4-clan > 3-clan (for $\mathrm{CuBr}_{2}$ and $\mathrm{ZnBr}_{2}$ ). The expected order would be: an $>3$-clan $>4$-clan because the inductive effect of the electron withdrawing chloro atom, which causes the diminution of the electronic density in the aromatic ring and of the electronic density available for the nitrogen atom linked to the ring. The chlorine atom withdraws more electronic density in the para-position than in the meta-position. This means that the $\bar{D}$ parameter is better than the $\Delta_{\mathrm{r}} H^{\theta}$ parameter for determining the basicity order. This could be due to the contribution of another kind of interaction in $\Delta_{\mathrm{r}} H^{\theta}$ like hydrogen bonding $(\mathrm{Cl}-----\mathrm{H})$ in the 3-clan addut.

\section{Conclusion}

Solid complexes were obtained through the interaction of 3 -chloroaniline with bromides of the first row of divalent transition metals. These complexes were decomposed upon heating. The determination of the enthalpies of solution of the adducts, salts and ligand leads to the estimation of the energies of the metal ion-nitrogen coordinated bonds. The values were between 82 and $119 \mathrm{~kJ} \cdot \mathrm{mol}^{-1}$. As a whole, the basic strength of 3-chloroaniline with respect to aniline and 4-chloroaniline is an $>3$-clan $>4$-clan, as it would be expected by the inductive effect of the electron withdrawing chlorine atom, which is stronger in the paraposition than that in the meta-position.

\section{Acknowledgements}

Majeed Khan thanks TWAS/CNPq organizations for a fellowship which made it possible for him to undertake the above research at the University of Campinas.

\section{REFERENCES}

[1] A. V. Ablov and L. V. Nazarova, "Effect of Functional Groups in the Ligand Molecule on the Stability of Complex Salts of Nickl," Zhurnal Neorganicheskoi Khimii, Vol. 5, 1960, pp. 1735-1737.

[2] A. V. Ablov and Z. P. Burnashava, "Addition Compounds of Aniline and Its Derivatives with Zinc Halide," Zhurnal Neorganicheskoi Khimii, Vol. 5, 1960, pp. 604-609.

[3] A. V. Ablov and V. Ya. Ivanova, "Addition Compounds of Aromatic Amines with Cadmium Halides" Zhurnal Neorganicheskoi Khimii, Vol. 6, 1961, pp. 883-889.

[4] S. R. Jain and S. Soundararajan, "Dipole Moments and Structure of Molecular Compounds of Zinc and Cadmium Halides," Current Science (India), Vol. 31, 1962, pp. 458-459.

[5] P. Spacu, V. Voicu and I. Pascaru, "Paramagnetic Resonance of Some Copper(II) Complexes," Journal of Chemical Physics, Vol. 60, 1963, pp. 368-873.

[6] S. R. Jain and S. Soundararajan, "Electric Polarization and Structure of Molecular Complexes of the Metallic Halides of Group II of the Periodic Table," Journal of Inorganic and Nuclear Chemistry, Vol. 26, 1964, pp. 1255-1261.

[7] D. P. N. Satchell and R. S. Satchell, "Spectroscopic Study of the Equilibrium in Acetone Solution between Zinc Halides and Aromatic Amines," Transactions of the Faraday Society, Vol. 61, 1965, pp. 1118-1126. http://dx.doi.org/10.1039/tf9656101118

[8] I. S. Ahuja, D. H. Brown, R. H. Nuttall and D. W. A. Sharp, "The Preparation and Spectroscopic Properties of Some Complexes Formed between Transition Metal Halides and Substituted Anilines," Journal of Inorganic and Nuclear Chemistry, Vol. 27, No. 7, 1965, pp. 1625-1634. http://dx.doi.org/10.1016/0022-1902(65)80026-4

[9] K. R. Monolov, "Thiocynate Complexes," Zhurnal Neorganicheskoi Khimii, Vol. 11, 1966, pp. 684-686.

[10] I. S. Ahuja, "Preparation and Spectroscopic Studies of Aniline, Substituted Anilines and Morpholine Complexes with Cobalt(II) Thiocynate," Indian Journal of Chemistry, Vol. 7, 1969, pp. 509-511.

[11] P. O. Dunstan, "Thermochemistry of Adducts of Some Bivalent Transition Metal Bromides with 4-Chloroaniline," Thermochimica Acta, Vol. 450, No. 1-2, 2006, pp. 5-11. http://dx.doi.org/10.1016/j.tca.2006.05.022

[12] U. G. da Silva, O. A. Oliveira and R. F. de Farias, "Synthesis, Characterization and Calorimetric Study of Zinc Group Halide Adducts with Aniline," Thermochimica Acta, Vol. 450, No. 1-2, 2006, pp. 2-4. http://dx.doi.org/10.1016/j.tca.2006.04.010

[13] T. S. Sikha and P. Indrasenan, "Thermal Decomposition Kinetics of Some Aniline Complexes of Zinc Group Metals," Indian Journal of Chemistry Section A, Vol. 43A, 2004, pp. 1393-1402. 
[14] E. Akalin and S. Akyuz, "Force Field and IR Intensity Calculation of Aniline and Transition Metas(II) Aniline Complexes," Journal of Molecular Structure, Vol. 482483, pp. $175-181$. http://dx.doi.org/10.1016/S0022-2860(98)00780-7

[15] K. R. Zurowski and M. Labanowska, "Coordination of Ammonia and Aniline by Copper(II) Chloride," Polish Journal of Chemistry, Vol. 69, 1995, pp. 998-1002.

[16] G. Beech, G. Marr and B. W. Rockett, "Thermochemical and Spectroscopic Properties of Transition-Metal Complexes," Journal of the Chemical Society A, Vol. 4, 1969, pp. 629-631.

[17] Sh. Dinkov and M. Arnaudov, "IR-Spectral Study of 2Aminopyridine and Aniline Complexes with Palladium (II)," Spectroscopy Letters, Vol. 32, No. 1, 1999, pp. 165180. http://dx.doi.org/10.1080/00387019909349975

[18] I. S. Malesnnikova and T. G. Balicheva, "IR-Spectroscopy Studies of the State of Water in Kaolin Ando $f$ the Processes of Kaolin Dehydration," Journal of Molecular Structure, Vol. 114, 1984, pp. 313-316. http://dx.doi.org/10.1016/0022-2860(84)87152-5

[19] S. Akyuz and J. E. D. Davies, "Solid-State Vibrational Spectroscopy. Part II. An Infrared and Raman Vibrational Spectroscopic Study of Metal(II) Halide Aniline Complexes," Journal of Molecular Structure, Vol. 95, 1982, pp. 157-168.

[20] P. C. Kong and F. D. Rochon, "Cis- and Trans-Platinium Complexes of Anilines," Inorganica Chimica Acta, Vol 61, 1982, pp. 269-271. http://dx.doi.org/10.1016/S0020-1693(00)89152-5

[21] M. Goldstein and R. J. Huges, "Vibrational Spectra of Some Bis(aniline)Complexes of Metal Dihalides Having Planar or Octahedral Halogen Bridged Chain Structures," Inorganica Chimica Acta, Vol. 40, 1980, pp. 229-237. http://dx.doi.org/10.1016/S0020-1693(00)92010-3

[22] J. Lee-Thorp, J.. E. Rueede and D. A. Thornton, "The Infrared Spectra $\left(3500-150 \mathrm{~cm}^{-1}\right)$ of Aniline Complexes of Cobalt(II), Nickel(II), Copper(II) and Zinc(II) Halides," Journal of Molecular Structure, Vol. 50, No. 1, 1978, pp. 65-71. http://dx.doi.org/10.1016/0022-2860(78)87097-5

[23] I. S. Ahuja, "Aniline Complexes of Cadmium(II) Acetate," Australian Journal of Chemistry, Vol. 21, No. 11, 1968, pp. 2805-2807. http://dx.doi.org/10.1071/CH9682805

[24] J. M. Haigh, M. A. Van Dam and D. A. Thorthon, "Complexes and Ligands II. Complexes of Mercury(II) and Zinc(II) with Primary Aromatic Amines: Infrared Spectra and Bonding," Journal of the South African Institute, Vol. 20, 1967, pp. 113-122.

[25] I. S. Ahuja, D. H. Brown, R. H. Nuttall and D. W. A. Sharp, "The Preparation and Properties of Some Aniline Complexes of Metal(II) Sulfates and Nitrates," Journal of the Chemical Society A, Vol. 7, 1966, pp. 938-941.

[26] M. A. J. Jungbauer and C. Curran, "Infrared Spectra of Complexes of Aniline with Metal(II) Halides," Spectrochimica Acta, Vol. 21, 1965, pp. 141-148.

[27] J. A. Riddick and W. B. Bunger, "Organic Solvents," 3rd Edition, Wiley, New York, 1970.
[28] J. B. Niederl and J. A. Sozzi, "Microanáslisis Elemental Orgánico," Methopress, Buenos Aires, 1958.

[29] I. M. Kolthoff and E. B. Sandall, "Tratado de Química Analítica Cuantitativa," 3rd Edición, Nigar, Buenos Aires, 1956.

[30] H. A. Flaschka, "EDTA Titrations: And Introduction to Theory and Practice," 2nd Edition, Pergamon Press, London, 1964.

[31] P. O. Dunstan, "Thermochemistry of Adducts of Bis(2,4pentanedionato)Zinc with Heterocyclic Amines," Journal of Chemical \& Engineering Data, Vol. 44, No. 2, 1999 , pp. 243-247. http://dx.doi.org/10.1021/je980113m

[32] E. F. Herington, "Recommended Reference Materials for the Realization of Physicochemical Properties (Recommendation Approved 1974)," Pure and Applied Chemistry, Vol. 40, 1974, pp. 391-450.

[33] D. A. Thornton, "Metal Complexes of Aniline: Infrared and Raman Spectra," Journal of Coordination Chemistry, Vol. 24, No. 3, 1991, pp. 261-289. http://dx.doi.org/10.1080/00958979109407887

[34] S. Akyuz and J. E. D. Davies, "Solid-State Vibrational Spectroscopy. Part 11. An Infrared and Raman Vibrational Spectroscopic Study of Metal(II) Halide Aniline Complexes," Journal of Molecular Structure, Vol. 95, 1982, pp. 157-168.

[35] J. Reedijk, P. W. N. M. Leeuwem and W. L. Groenveld, "A Semiempirical Energy-Level Diagram for Octahedral Nickel Complexes," Recueil des Travaux Chimiques des Pays-Bas, Vol. 87, 1968, pp. 129-141.

[36] A. B. P. Lever, "Electronic Spectra of Some Transition Metal Complexes," Journal of Chemical Education, Vol. 45, 1968, pp. 711-712.

[37] M. W. G. Bolster, "The Coordination Chemistry of Amino-Phosphinoxide and Related Compounds," Thesis, Leiden, 1972, pp. 88-89, 95, 98, 100.

[38] P. O. Dunstan, "Thermochemistry of Morpholine Adducts of Some Bivalent Transition Metal Bromides," Journal of Chemical \& Engineering Data, Vol. 54, 2009, pp. 842-846.

[39] T. N. Sevast'yanova and A. V. Suvorov, "The Structure and Thermal Stability of Group III Halide Complexes with Pyridine," Russian Journal of Coordination Chemistry, Vol. 25, 1999, pp. 679-688.

[40] P. O. Dunstan, "Thermochemistry of Adducts of Some Bivalent Transition Metal Bromides with Quinoline," Thermochimica Acta, Vol. 468, 2008, pp. 21-6.

[41] P. O. Dunstan, "Thermochemistry of Aniline Derivatives Complexes of Arsenic Trihalides," Thermochimica Acta, Vol. 268, 1995, pp. 83-93.

[42] D. D. Wagman, W. H. Evans, V. B. Parker, R. H. Schumm, I. Hallow, S. M. Churney and R. L. Nuttall, "The NBS Table of Chemical Thermodynamic Properties. Selected Values for Inorganic and $\mathrm{C}_{1}$ and $\mathrm{C}_{2}$ Organic Substances in SI Units," Journal of Physical and Chemical Reference Data, Vol. 2, 1982, pp. 50-191.

[43] P. O. Dunstan, "Thermochemistry of Adducts of Some Bivalent Transition Metal Bromides with Aniline," Thermochimica Acta, Vol. 441, 2006, pp. 1-7. 